ВОРОНЦОВ Сергей Алексеевич - доктор юридических наук, профессор, руководитель Научноучебного центра противодействия коррупции Института права и национальной безопасности Российской академии народного хозяйства и государственной службы при Президенте РФ (119571, Россия, г. Москва, пр-кт Вернадского, 82, стр. 1; vorontsov@uriu.ranepa.ru)

ПОНЕДЕЛКОВ Александр Васильевич - доктор политических наук, профессор, заведующий лабораторией проблем повышения эффективности государственного и муниципального управления Южно-Российского Института управления - филиала РАНХиГС при Президенте РФ (119571, Россия, г. Москва, пр-кт Вернадского, 82, стр. 1; ропеdelkov@игіи.ranера.ru); заслуженный деятель науки РФ

\title{
ПРОТИВОДЕЙСТВИЕ КОРРУПЦИИ: РЕПРЕССИИ ИЛИ ЦИФРОВИЗАЦИЯ?
}

\begin{abstract}
Аннотация. В статье авторы, опираясь на материалы экспертного опроса, проведенного в февралемарте 2020 г. лабораторией проблем повышения эффективности государственного и муниципального управления ЮРИУ РАНХиГС (г. Ростов-на-Дону) и Научно-учебным центром противодействия коррупции ИПНБ РАНХиГС (г. Москва) в 13 субъектах РФ, исследуют актуальные вопросы восприятия населением содержания коррупции в современный период, оценивают действенность мер, направленных на блокирование причин и факторов, способствующих сохранению и воспроизводству коррупционных отношений, формулируют необходимость использования в противодействии данному феномену антикоррупционных цифровых технологий.
\end{abstract}

Ключевые слова: коррупция, противодействие, причины, факторы, эксперты, опрос, антикоррупционные меры, наказание, цифровизация, просвещение

$3^{2}$ последние годы в Российской Федерации проделан значительный объем работы по выявлению, предупреждению и пресечению правонарушений коррупционного характера. Так, организована работа по анализу доходов и расходов должностных лиц, внедрена система запретов, ограничений и обязанностей, установленных в целях противодействия коррупции, развернута масштабная программа антикоррупционного и правового просвещения. Активно включились в работу подразделения кадровых служб федеральных государственных органов по профилактике коррупционных и иных правонарушений. Существенно активизирована работа правоохранительных органов, по материалам которых суды рассмотрели тысячи уголовных дел, связанных с дачей и получением взяток, превышением полномочий, мошенничеством, присвоением и растратой. Однако, несмотря на принятые меры, число преступлений коррупционной направленности в 2019 г. в нашей стране увеличилось на 1,6\%, в т.ч. связанных со взятками - на $10,7 \%$, с посредничеством при взятках - на 32,5\%1. В первые месяцы 2020 г. рост коррупции в России продолжился - так считают 24,2\% участников опроса, проведенного в 36 регионах службой специальной связи и информации Федеральной службы охраны $(Ф С О)^{2}$.

В целях исследования особенностей восприятия населением содержания коррупции в современный период, оценки действенности антикоррупционных мер, направленных на блокирование причин и факторов, способствующих сохранению и воспроизводству коррупционных отношений, поиска более эффективных путей противодействия данному феномену лаборатория проблем

1 Число выявленных взяток в России в 2019 году выросло на 10\%. - TACC. 28.01.2020 Доступ: https://tass.ru/proisshestviya/7622875 (проверено 25.05.2020).

2 Опрос ФСО. Почти четверть россиян заявили о росте коррупции с начала 2020 года. - PASMI.RU. 25.05.2020. Доступ: https://pasmi.ru/archive/270321/ (проверено 29.05.2020). 
повышения эффективности государственного и муниципального управления Южно-Российского института управления - филиала РАНХиГС (г. Ростовна-Дону) и Научно-учебный центр противодействия коррупции Института права и национальной безопасности РАНХиГС при Президенте РФ 17-18 апреля 2020 г. в Ростове-на-Дону провели научно-практическую конференцию с международным участием «Противодействие коррупции на государственном и муниципальном уровне в современной России» [Противодействие... 2020а]. В процессе подготовки данного мероприятия в феврале-марте 2020 г. осуществлен социологический опрос методом анкетирования в 13 субъектах РФ, в котором приняли участие 1080 экспертов.

В настоящей статье проанализированы результаты социологического опроса в Ростовской обл., которые сопоставимы с данными, полученными по другим субъектам. В опросе приняли участие 270 экспертов:

- по возрастному признаку: до 29 лет - 16,7 \%; от 30 до 49 лет - 32,3\%; от 50 до 59 лет $-32,5 \%$; от 60 и старше $-18,5 \%$;

- по полу: мужчин - 45,6 \%, женщин - 54,4 \%;

- по роду деятельности: представители органов государственной власти и местного самоуправления - 23,7\%; работники сферы науки и образования - 12,8\%; специалисты юридического профиля (адвокаты, юристы) - 12,4\%; представители судебной системы и правоохранительных органов - 8,2\%; члены общественных организаций - 16,9\%; члены политических партий $12,4 \%$; представители СМИ - 13,6\%;

- по стажу работы в должности: до 5 лет - 20,3\%; от 5 до 10 лет -22,4\%; от 10 до 20 лет - 26,2\%; от 20 до 30 лет - 23\%; свыше 30 лет - 8,1\%.

Анализ результатов социологического опроса [Противодействие... 2020б] позволил выделить некоторые изменения, происшедшие в восприятии экспертами отдельных аспектов коррупции, по сравнению с аналогичными социологическими опросами, имевшими место в предыдущие годы [Проблемы... 2018а; Проблемы... 2018б].

1. По мнению экспертов, коррупция в настоящее время не воспринимается в качестве наиболее острой проблемы, волнующей население, значительная часть которого, вероятно, смирились с неизбежностью данного явления, поэтому ни громкие аресты высокопоставленных чиновников, ни изымаемые у них миллиарды (тонны) рублей уже не сказываются на остроте оценки. Более высокие ранговые позиции эксперты отвели плохому качеству дорог, ухудшению экологической обстановки, высоким ценам на товары и услуги, низкому уровню заработной платы и задержкам ее выплаты, плохому состоянию больниц, поликлиник и медпунктов, росту безработицы, проблемам в сфере жилищно-коммунального хозяйства и пр.

Характеризуя содержание коррупции, почти половина экспертов указали получение или дачу взятки (что традиционно для нашей страны). На вторую ранговую позицию участники опроса поставили использование должностного положения в личных корыстных целях. Обращает на себя внимание тот факт, что подарки должностным лицам, которые, согласно предыдущим опросам, значительная часть экспертов не воспринимала в качестве проявления коррупции, в настоящем исследовании поставлены на третью ранговую позицию, что может свидетельствовать о действенности антикоррупционного просвещения. При этом до 25\% экспертов оправдывают подарки национальной традицией и искренним желанием отблагодарить чиновника за оказанную услугу. 27,7\% экспертов считают, что подарок - единственный путь решить проблему и сберечь время и нервы.

В качестве значимых элементов содержания коррупции эксперты также 
выделили использование чиновниками государственных и муниципальных средств в личных целях, а также различные формы передачи государственного имущества частным владельцам.

2. В последние годы в отечественную антикоррупционную практику внедрены соответствующие правовые стандарты и инструменты, направленные на своевременное выявление и предупреждение коррупционных рисков. Научное сообщество активно исследует возможность использования искусственного интеллекта в противодействии коррупции. Так, на Гайдаровском форуме, прошедшем в РАНХиГС в начале 2020 г., обсуждению вопросов, связанных с формированием эффективных правовых, организационных и цифровых механизмов противодействия коррупции, была посвящена экспертная дискуссия «Цифровизация права = общество без коррупции?»1. Эксперты полагают, что цифровизация способна существенно повысить транспарентность государственного управления, помочь в выявлении коррупционных отношений, оптимизировать деятельность субъектов противодействия коррупции.

В современной России это весьма актуально, что подтвердили и эксперты, поставившие на первую ранговую позицию при характеристике причин коррупции «недостаточно строгий контроль за действиями чиновников, их доходами и расходами».

На второй ранговой позиции эксперты видят «неадекватность наказания за факты коррупции», что свидетельствует о недостаточности одной только «неотвратимости наказания» для предупреждения преступлений коррупционного характера. По нашему мнению, в обществе сформирован запрос на обеспечение адекватности наказания, которая во многих случаях, касающихся высокопоставленных коррупционеров, а также «представителей творческой интеллигенции», по мнению экспертов, не срабатывает, и фигуранты резонансных уголовных дел отделываются условными сроками, сохраняя награбленное. Очередной пример - приговор Мещанского районного суда Москвы по уголовному делу в отношении художественного руководителя Гоголь-центра К. Серебренникова, которого за хищение 129 млн руб. приговорили к 3 годам условного срока 2 .

На третью позицию эксперты вывели «низкую заработную плату работников бюджетной сферы», что подтверждает слова одного из героев Бертольда Брехта: «сначала хлеб, а нравственность потом» 3 .

3. Повышенную опасность коррупции для личности, общества, государства эксперты видят в том, что коррупция резко снижает уровень политической лояльности граждан к государству, его политическим лидерам и представителям власти на местах, поскольку часть высокопоставленных чиновников не соблюдают закон, игнорируют принципы права и справедливости. По своей сути коррупция лишает смысла институты государства, подменяя противоправными механизмами публичные управленческие и правовые процедуры.

На вторую ранговую позицию эксперты поставили утверждение, что коррупция уничтожает понятия нравственности, честности, справедливости. Эксперты видят опасность коррупции в том, что она способствует распространению в обществе противоправного мировоззрения - нигилизма, поскольку

${ }^{1}$ Цифровизация права = общество без коррупции? 2020. Доступ: https://gaidarforum.ru/ program/16-yanvarya/tsifrovizatsiya-prava-obshchestvo-bez-korruptsii/ (проверено 20.08.2020).

2 Дело Серебренникова и «Седьмой студии». Приговор. - Медиазона. 26.06.20. Доступ: https://zona.media/online/2020/06/26/serebrennikov_final (проверено 20.08.2020).

3 Парижева 3. 2018. Бертольд Брехт. Доступ: https://www.litprichal.ru/work/318155/ (проверено 20.08.2020). 
раз законы не обязательны для отдельных представителей коррумпированной элиты, значит, их можно не соблюдать и населению.

43,7\% экспертов оценивают уровень коррупции в нашей стране и ее распространенность в государственных структурах как очень высокий. В противовес данному мнению треть экспертов считают, что уровень коррупции в России заметный, но за последние годы он существенно снизился.

$21,5 \%$ экспертов настроены оптимистично и полагают, что проблема коррупции в России практически искоренена, происходят лишь отдельные частные случаи взяточничества.

Примерно поровну распределились мнения экспертов по вопросу о влиянии коррупции на их жизнь. Так, более половины экспертов считают, что коррупция либо не оказывает влияния на их жизнь, либо оказывает незначительное влияние. Лишь каждый четвертый эксперт убежден, что коррупция воздействует на весь спектр отношений в государстве и обществе, следовательно, оказывает влияние и на жизнь индивидов. На наш взгляд, подобное распределение мнений экспертов свидетельствует о необходимости совершенствования антикоррупционного просвещения в части разъяснения сущности коррупции и необходимости формирования неприятия населением коррупционных механизмов.

4. При анализе влияния коррупции на различные сферы жизни (экономика, политика, бизнес) мнения экспертов разделились поровну: половина экспертов считают, что коррупция оказывает влияние на данные сферы, другая половина убеждена, что не оказывает либо оказывает незначительное влияние. В обоих случаях подобные оценки могут быть объяснены либо реальным снижением уровня коррупции в стране, либо, что более реально, «привыканием» населения к существованию коррупционных механизмов как неизбежного элемента современной жизни.

В числе представителей наиболее коррумпированных профессий эксперты на первую ранговую позицию ожидаемо поставили сотрудников ГИБДД, затем следуют чиновники, выделяющие участки под коммерческую деятельность и жилищное строительство, работники местных администраций, работники прокуратуры, военкоматов, сотрудники ФСИН, таможенных органов, Роспотребнадзора, ГПН, судьи районных и областных (краевых) судов, врачи и медицинские работники. Упоминаемые в отчетах правоохранительных органов в качестве наиболее коррумпированной категории учителя и директора школ в восприятии экспертов таковыми не являются и занимают последнее место в рейтинге коррумпированных профессий.

5. В течение последнего года лично сталкивались с коррупционными проявлениями не более 1/3 экспертов. Представляется, это недопустимо высокий показатель, который свидетельствует, что потенциальные взяточники не озабочены усилением репрессивных мер за коррупционные правонарушения либо меры антикоррупционного просвещения пока не оказали должного сдерживающего воздействия на потенциальных коррупционеров, а следовательно не привели к ощутимому снижению уровня восприятия коррупции.

Заслуживает внимания мнение 2/3 экспертов, считающих, что они не защищены или защищены лишь в некоторой степени от «административного произвола коррумпированных чиновников», которые дают подчиненным поручения коррупционного характера, угрожая увольнением в случае невыполнения. Лишь 24,1\% экспертов убеждены в своей «абсолютной защищенности».

В качестве несомненно позитивного элемента опроса следует отметить, что по сравнению с ранее проведенными исследованиями ощутимо снизилось число граждан, которые ни при каких обстоятельствах не станут сооб- 
щать о фактах коррупции (14,1\%). Ранее этот показатель был на уровне $30 \%$ и более.

В качестве мер реагирования на ставшие известными коррупционные проявления каждый пятый эксперт выбрал вариант: «обращусь в правоохранительные органы»; примерно столько же готовы воспользоваться телефоном доверия. В целом, 3/4 экспертов готовы к сотрудничеству с органами власти в противодействии коррупции. 11,3\% экспертов готовы проинформировать органы власти анонимным письмом.

Позицию граждан, отказывающихся информировать органы власти о фактах коррупции, эксперты объясняют опасением за свою безопасность и безопасность своих близких, навешиванием в ближайшем окружении ярлыка «доносчика и стукача», а также неверием в то, что в отношении коррупционеров будут приняты реальные меры.

В качестве ситуации, при которой людям приходилось давать взятку, эксперты поставили на первую позицию стремление урегулировать проблемы с ГБДД. На второй позиции - желание добиться желаемого результата в суде, на третьей - урегулирование проблем с военкоматом, устройство на работу и продвижение по службе. В целом, перечень ситуаций, в которых людям приходится прибегать к использованию коррупционных механизмов, показывает широкий спектр реально существующих коррупционных рисков, требующих внимания государственных органов и общественных структур, задействованных в противодействии коррупции.

6. Одним из эффективных направлений противодействия коррупции является использование возможностей цифровизации для исключения контактов потенциальных взяткодателей и взяткополучателей. Серьезную помощь в этом могут оказать широко внедряемые в нашей стране технологии «единого окна», обеспечивающие «прозрачность» операций, что создает определенные гарантии от коррупции. Почти 2/3 экспертов отметили, что пользуются услугами, предоставляемыми в электронном виде через Интернет (оплата услуг ЖКХ, штрафов ГИБДД, постановка на очередь в дошкольное учреждение, предварительная запись на получение заграничного паспорта и пр.). При этом столько же экспертов указали, что не считают услуги в электронном виде гарантией от коррупции, т.к. коррумпированные чиновники находят пути незаконного решения возникающих вопросов.

Около $15 \%$ экспертов, вероятно, пожилого возраста, предпочитают использовать традиционные методы получения услуг. $13 \%$ указали, что не знают о подобных услугах, и 12,2\% не умеют пользоваться предлагаемыми технологиями, что показывает наличие резервов в реализации рассматриваемого направления.

7. Более $90 \%$ экспертов владеют информацией о мерах противодействия коррупции в полном объеме либо частично. Только $8,1 \%$ указали, что не знакомы с подобной информацией. Приведенные цифры свидетельствуют о действенности антикоррупционного просвещения и показывают наличие неиспользованных резервов.

Меры, регламентированные Ф3 «О противодействии коррупции», считают эффективными около $10 \%$ экспертов. Более 1/3 экспертов согласны с подобной оценкой, но отмечают, что антикоррупционные меры не всегда соблюдаются. Еще 1/3 экспертов считают меры по профилактике коррупции скорее эффективными, но не реализуемыми на практике. 19,3\% экспертов полагают, что рассматриваемые меры абсолютно неэффективны.

В качестве позитива следует отметить, что по сравнению с аналогичными опросами, проведенными в прошлые годы, существенно сократилось число 
экспертов, не знакомых с текстом Ф3 «О противодействии коррупции». Так, если в 2018 г. данный показатель по Ростовской обл. составлял 26,1\%, то в текущем году $-8,1 \%$.

В числе эффективных мер, направленных на борьбу с коррупцией, эксперты выделили: увольнение должностного лица, уличенного в коррупции; предание суду взяточников и коррупционеров; совершенствование антикоррупционного законодательства; антикоррупционную пропаганду в СМИ; публичные заседания Комиссии по координации работы по противодействию коррупции в субъекте РФ; создание механизмов общественного контроля за соблюдением чиновниками антикоррупционного законодательства.

Эффективность деятельности Фонда борьбы с коррупцией Алексея Навального отметили 3,7\% экспертов, что показывает отсутствие широкого интереса общественности к данному актору.

В качестве основного источника информации о противодействии коррупции эксперты указали газеты, телевидение и радиовещание. Далее следуют информационно-телекоммуникационная сеть Интернет и сайты органов государственной (муниципальной) власти.

Каждый пятый эксперт удовлетворен качеством и объемом информации, получаемой из федеральных СМИ. 2/3 экспертов считают, что информации недостаточно и она освещает не все аспекты антикоррупционной проблематики. Аналогичная картина существует и в местных СМИ, к которым у экспертов интерес ниже, чем к федеральным.

8. В числе государственных и общественных институтов, наиболее эффективно противодействующих коррупции в России, 24,1\% экспертов поставили на первую позицию Федеральную службу безопасности РФ, затем следует Прокуратура РФ и иные правоохранительные органы.

11,9\% экспертов выделили в противодействии коррупции роль институтов гражданского общества. Замыкают рейтинг органы государственной власти и местного самоуправления, которые явно недооценены экспертами в качестве субъектов противодействия коррупции, несмотря на значительный объем работы, осуществляемый ими.

Как и в социологических опросах прошлых лет, основная часть экспертов, отвечая на вопрос о задержаниях чиновников, бравших взятки в особо крупном размере, считают эти эпизоды не следствием последовательной антикоррупционной политики государства и общества, а «показательными постановками» для создания видимости борьбы с коррупцией. Чуть больше $20 \%$ экспертов считают, что были задержаны те чиновники, которые не отчисляли процент вышестоящему руководству. И только 1/4 экспертов думают, что «резонансные» задержания связаны с системной борьбой с коррупцией.

9. Оценивая меры, которые могут привести к снижению уровня коррупции в российском обществе, эксперты ранжировали первые 5 позиций в следующей последовательности:

1) установить пожизненный запрет на государственную службу для чиновников, осужденных за преступления коррупционного характера;

2) повысить эффективность деятельности правоохранительных органов по борьбе с коррупцией за счет введения в оперативно-розыскную практику «провокации взятки»;

3) жестко контролировать распределение и расход бюджетных средств;

4) повысить правовую грамотность населения в плане антикоррупционной составляющей;

5) ввести правило полной конфискации имущества не только осужденного за коррупционное преступление, но и его ближайших родственников. 
Несложно отметить склонность экспертов к репрессивному пути решения проблемы, т.к. этот путь представляется более простым и быстрым по сравнению с воспитательным аспектом.

В отношении наказания лиц, изобличенных во взяточничестве, в качестве первой ранговой позиции более половины экспертов считают, что наказание должно быть одинаковым для всех чиновников вне зависимости от их ранга. Данная позиция всего лишь на $3 \%$ опередила мнение, что чиновники более высокого ранга, приносившие присягу, должны быть наказаны за взяточничество строже, чем простые граждане.

На третью позицию эксперты поставили ответ, что наказание, обозначенное в Уголовном кодексе, вполне соответствует характеру деяния.

Следует отметить, что возросло число экспертов, осознающих неэффективность репрессивных мер противодействия коррупции. Одновременно в 4 раза возросло число экспертов, затруднившихся с ответом, что свидетельствует об определенной растерянности экспертов в выборе дальнейших путей противодействия коррупции, т.к. жесткие меры не пугают потенциальных взяточников.

Поэтому в числе предложений в отношении мер, которые необходимо принять для снижения уровня коррупции, эксперты, наряду с ужесточением законодательства, указали формирование антикоррупционного мировоззрения, повышение правовой грамотности населения, внедрение современных мер противодействия (цифровизация).

10. Позитивным итогом социологического опроса по сравнению с аналогичными исследованиями прошлых лет является готовность 93\% экспертов принять личное участие в антикоррупционных мероприятиях. Каждый пятый эксперт уже участвует в подобной работе и считает это своим гражданским долгом.

Учитывая изложенное выше, можно констатировать, что антикоррупционная политика не в полной мере соответствует остроте рассматриваемой угрозы безопасности. Законотворческая и правоприменительная деятельность в сфере противодействия коррупции систематически демонстрирует не противодействие, а компромисс. Это отрицательно сказывается на авторитете государственных органов, отвечающих за решение задач в сфере борьбы с коррупцией, провоцирует у части граждан правовой нигилизм, нежелание принимать участие в данной работе, что затрудняет решение проблемы формирования в обществе нетерпимости к коррупционным проявлениям.

Необходимо повысить эффективность противодействия коррупции за счет разработки и внедрения дополнительных механизмов и инструментария противодействия коррупции. В этой связи большие надежды связаны с внедрением антикоррупционных цифровых технологий, т.к., по мнению президента России В. Путина, «цифровизация всей системы государственного управления, повышение ее прозрачности - это и мощный фактор противодействия коррупции» 1 .

Статья подготовлена в рамках выполнения научноисследовательской работы по государственному заданию РАНХиГС при Президенте России по теме 5.6. «Разработка системы мер и юридических механизмов противодействия коррупции в условиях ицировизации государственного управления и экономики».

1 Послание Президента Федеральному Собранию 1 марта 2018 года. Доступ: http:// kremlin.ru/events/president/news/56957 (проверено 20.08.2020). 


\section{Список литературы}

Проблемы противодействия коррупции на государственной и муниципальной службе и пути их решения в современной России: материалы круглого стола с международным участием. 2018а. Ростов н/Д. 482 с.

Проблемы противодействия коррупиии на государственной и муниципальной службе и пути их решения в современной России: информационно-аналитические материалы круглого стола с международным участием. 2018б. Ростов н/Д. Изд-во ЮРИУ РАНХиГС. 128 с.

Противодействие коррупции на государственном и муниципальном уровне в современной России: материалы всероссийской научно-практической конференции с международным участием. 17 апреля 2020 г. 2020а. Ростов н/Д: Изд-во ЮРИУ РАНХИГС. 320 с.

Противодействие коррупции на государственном и муниципальном уровне в современной России: информационно-аналитические материалы всероссийской научно-практической конференции с международным участием. 17 апреля 2020 г. 2020б. Ростов н/Д: Изд-во ЮРИУ РАНГиГС. 240 с.

VORONTSOV Sergei Alekseevich, Dr.Sci. (Legal), Professor, Head of the Scientific and Educational Center for Combating Corruption, Institute of Law and National Security, Russian Presidential Academy of National Economy and Public Administration (RANEPA) (bld. 1, 82 Vernadskogo Ave, Moscow, Russia, 119571; vorontsov@uriu.ranepa.ru) PONEDELKOV Aleksandr Vasil'evich, Dr.Sci. (Pol.Sci.), Professor, Head of the Laboratory for Improving the Efficiency of State and Municipal Administration, South Russian Institute of Management - Branch of Russian Presidential Academy of National Economy and Public Administration (RANEPA) (bld. 1, 82 Vernadskogo Ave, Moscow, Russia, 119571; ponedelkov@uriu.ranepa.ru); Honored Scientist of the Russian Federation

\section{THE COUNTERACTION TO CORRUPTION: EITHER THE REPRESSION OR DIGITALIZATION?}

\footnotetext{
Abstract. On the base of materials of an expert survey conducted in February-March 2020 by the Laboratory of the Law Institute (RANEPA, Rostov-on-Don) and the Scientific and Educational Center for Combating Corruption (RANEPA, Moscow) in 13 subjects of Russia, the authors investigate current issues of the perception of the content of corruption by the population in the modern period. They evaluate the effectiveness of measures aimed at blocking the causes and factors contributing to the preservation and reproduction of corruption; formulate the need to use anti-corruption digital technologies in countering this phenomenon.

Keywords: corruption, counteraction, reasons, factors, experts, survey, anti-corruption measures, punishment, digitalization, education
} 